\title{
Experiencias
}

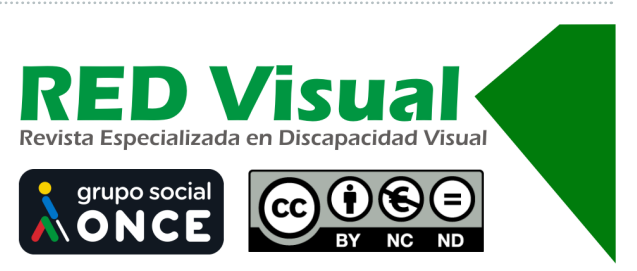

Recepción: 29-12-2020

Aceptación: 06-05-2021

\section{El cuento viajero: lecturas adaptadas para compartir e intercambiar entre el alumnado con discapacidad visual y su entorno ${ }^{1}$}

The travelling story: adapted texts to share and exchange between visually impaired pupils and their environment

\author{
M. I. Alcántara Moreno, F. Bello Díaz, J. Blanca Castillo, \\ M. B. Díaz Corpas, M. C. Fernández Fernández, A. Gámez Martos, \\ M. D. López Albusac, A. Moreno Batres
}

\section{Resumen}

El presente trabajo se basa en una actividad educativa que sigue desarrollándose desde el año 2016 y que fue puesta en marcha por el Club Braille. Está orientado a consolidar la lectura con los alumnos de las etapas de educación infantil y primer ciclo de primaria usuarios del braille, implicando a la familia en el desarrollo y el mantenimiento del gusto por la lectura. Para ello, se presenta un cuento viajero que es manipulado y sobre el que, tras su lectura, debe aportarse un trabajo (audio, dibujo, representación, manualidad, etc.). El objetivo principal de este proyecto va orientado a consolidar la lectura como un elemento de disfrute personal, potenciando la comprensión lectora y, a su vez, poder mejorar el nivel de vocabulario y ortografía. Aunque la Tifloteca dispone de diversos recursos para la lectura de textos literarios e informativos en formato impreso, audiovisual o multimedia, el proyecto, también incluye la realización de cuentos en braille accesibles, adaptados y creados por el equipo educativo que hace posible que nuestros alumnos dispongan de más recursos motivantes para conseguir el objetivo principal: aprender con materiales adaptados a sus necesidades que les ayuden a desarrollar sus competencias, así como acceder al aprendizaje gracias a la inclusión.

1 Trabajo galardonado con el segundo premio en la categoría General del V Concurso de Experiencias de Innovación y Buenas Prácticas en Servicios Sociales de la ONCE, presentado bajo el título El cuento viajero.

Alcántara, M.I., Bello, F., Blanca, J., Díaz, M.B., Fernández, M.C., Gámez, A., López, M.D., y Moreno, A. (2021). El cuento viajero: lecturas adaptadas para compartir e intercambiar entre el alumnado con discapacidad visual y su entorno. RED Visual: Revista Especializada en Discapacidad Visual, 78, 69-82. https://doi.org/10.53094/ISGJ8985. 


\title{
Palabras clave
}

Cuentos multiformato. Desarrollo táctil. Recursos inclusivos. Fomento de la lectura. Lectoescritura braille. Club de lectura. Comunidad educativa.

\begin{abstract}
This work is based on an educational activity that has been ongoing since 2016 and which was launched by the Braille Club. It is aimed at consolidating reading with pupils in infant and primary education who use Braille, involving their families in developing and maintaining a love of reading. To do this, a travelling tale is presented and manipulated and, after reading it, a piece of work (audio, drawing, theatre, craftwork, etc.) must be provided. The main objective of this project is to consolidate reading as a source of personal enjoyment, promoting reading comprehension while improving vocabulary and spelling. Although the Tifloteca has various resources for reading literary and informative texts in printed, audio-visual or multimedia format, the project also includes the creation of accessible Braille stories, adapted and created by the educational team, which provide our pupils with more stimulating resources to achieve the main objective: learning with materials adapted to their needs that help them to develop their skills, and access to learning thanks to inclusion.
\end{abstract}

\section{Key words}

Multi-format stories. Tactile development. Inclusive resources. Encouraging reading. Braille reading and writing. Reading Club. Educational community.

\section{Presentación}

Si quieres que tu hijo sea inteligente, léele cuentos. Si quieres que sea más inteligente, léele más cuentos.

Albert Einstein

\subsection{Introducción}

A través del Club Braille² de la Dirección de Apoyo (DAP) de la ONCE en Jaén, se habían puesto en marcha diversos Talleres de Lectura para adultos y menores escolares (ciclos $2 .^{\circ}$ y $3 .{ }^{\circ}$ de educación primaria y todos los ciclos de la ESO).

2 El Club Braille es, básicamente, un espacio físico y temporal de encuentro destinado a favorecer y fomentar la práctica y difusión del braille mediante actividades programadas a tal fin. 
No obstante, nos planteábamos qué podíamos hacer con el alumnado de educación infantil y primer ciclo de educación primaria, pero nos preguntábamos: ¿por qué queríamos realizar alguna actividad con este alumnado?, ¿qué queríamos hacer con ellos? y ¿cómo lo íbamos hacer?

Ante estas preguntas, surgió El cuento viajero.

¿Por qué? Porque buscábamos que este alumnado disfrutara del placer de «tocar» el cuento.

¿Qué queríamos hacer con ellos?, que este alumnado se sintiera importante y disfrutara más de la lectura, a través de una actividad motivadora.

¿Cómo? Utilizando cuentos multiformato ${ }^{3}$ adaptados por el Servicio Bibliográfico de la ONCE $(\mathrm{SBO})^{4}$ y disponibles en la Tifloteca, ${ }^{5}$ así como los confeccionados por el equipo educativo.

Los talleres de lectura para niños son una gran opción, un complemento para la escuela, además de las actividades deportivas. Cada una de ellas contribuirá a la formación integral de este alumnado (Boix y Viché, 1990).

También, constituyen un espacio donde divertirse, potenciar su imaginación; debemos acercarlos a la lectura desde muy pequeños.

Un cuento o un libro permiten a un niño escaparse a un mundo donde su imaginación y los personajes lo conducen a maravillosas experiencias y aprendizajes. A través de la lectura y los objetos que componen los cuentos facilitamos la interacción del niño y el desarrollo de su imaginación (Figura 1).

No podemos obviar el potencial de los cuentos como herramienta para abordar muchísimos aspectos con los niños: emociones, valores, diferentes situaciones que se pueden trasladar a la vida... (Bilbao, 2015).

3 Cuentos para niños adaptados en braille, tinta y relieve.

4 Centro especializado que coordina funcionalmente el conjunto de recursos humanos y materiales que la ONCE destina al fomento de la lectura y a la adaptación de todo tipo de recursos bibliográficos y documentos, en braille, sonido y relieve, para el acceso a la información escrita, y favorecer, así, la plena autonomía personal e inclusión social de las personas con discapacidad visual afiliadas a la ONCE, en cualquier aspecto de su vida, y siempre bajo los correspondientes estándares de calidad.

5 Denominación de las bibliotecas territoriales de la ONCE. Espacio para los fondos en braille, pero también para encuentros, jornadas de debate, presentaciones de libros, talleres de lectura, exposiciones, etc. Lugar de uso habitual del Club Braille. Más que un espacio, es un concepto. 
Figura 1. Niña leyendo el cuento Pipo y el diente

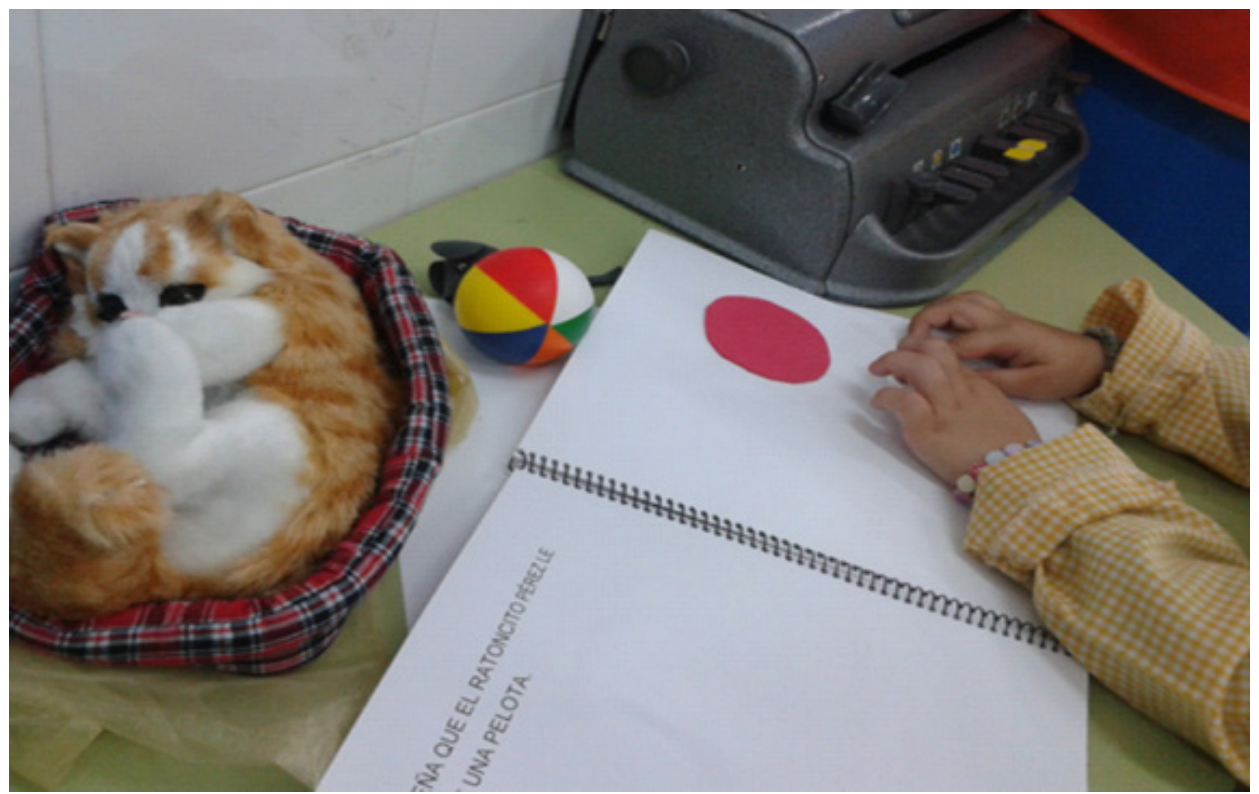

\subsection{Justificación}

La lectura es un instrumento de crecimiento personal que estimula la imaginación, la creatividad, capaz de enriquecer tanto la comprensión como la expresión oral y escrita, una fuente inagotable de placer.

Por ello, leer ayuda a que los niños estimulen su imaginación y su creatividad, a que sientan más interés por las cosas que les rodean; mejora su vocabulario, desarrolla las áreas cognitivas, fundamentalmente el lenguaje y las emociones. Les permite adquirir conocimientos y la posibilidad de experimentar sensaciones y sentimientos con los que disfrutar, madurar, aprender, reír y soñar.

Además, si los padres comparten el momento de la lectura de un cuento con sus hijos, estarán estableciendo un lazo especial entre ambas partes, a los niños les encanta escuchar la voz de sus padres, utilizando un tono suave y calmado con el que se consigue un efecto relajante que les ayudará, entre otras cosas, a conciliar el sueño por las noches. Por este motivo, es muy importante, desde muy pequeños, antes de comenzar a aprender a leer, inculcarles el hábito de la lectura. Es imprescindible, fomentar en los niños el amor por la lectura. Por ello, la motivación es primordial para iniciarlos en el proceso lectoescritor (Simon, 1994). 
Además, hay que tener en cuenta que, generalmente, los niños videntes muestran un gran interés por la técnica lectora debido a que, desde edades muy tempranas, están familiarizados con los materiales escritos (Simon, 1994). Siempre tienen muchos cuentos y libros a su disposición: en librerías, en bibliotecas, en grandes almacenes, en casa; ven dibujos y textos continuamente. Muchas familias les leen cuentos mientras ellos observan los dibujos, las imágenes y textos escritos, de tal manera que, poco a poco, van entendiendo que las palabras que se dicen también se escriben, despertando así su interés para aprender a leer.

Este proceso no se produce tan fácilmente con los alumnos ciegos o deficientes visuales graves que necesitan usar el código braille como principal sistema lectoescritor; es decir, no cuentan con tantos recursos, con tantas posibilidades (cuentos, libros, carteles...), por lo que se planteó realizar una actividad para apoyar a las familias y a los niños en esta tarea, ofreciéndoles múltiples oportunidades para poder acceder a un mayor número de cuentos.

Así pues, se plantea que el alumnado en la etapa de educación infantil y primer ciclo de educación primaria, posibles usuarios de braille en un futuro, reciban un cuento infantil, a modo de préstamo, para ser tocado, visto, contado, leído, releído y jugado por cada niño y niña junto a su familia. Tras la lectura del mismo, los niños pueden dar su opinión de lo que más les ha gustado, mediante una pequeña carta, tarjeta, un audio..., en colaboración con sus padres, e incluso pueden aportar alguna manualidad, juguete, etc. Con ello, pretendemos que, cuando lo reciba otro niño, otra familia, puedan comprobar que este cuento lo ha tenido, leído, otro niño, hecho este que siempre les hace mucha ilusión, ya que pueden comprobar tanto las familias como los propios niños que hay otros que también leen en braille.

Otra finalidad es la de ser utilizado como recurso para ser presentado a sus compañeros del aula para dar a conocer los cuentos escritos en braille, y así sensibilizarles desde muy pequeños con este sistema.

\subsection{Objetivos}

El objetivo general que se pretende conseguir con este proyecto es fomentar la lectura entre el alumnado con discapacidad visual y, para ello, se requiere la concreción de este objetivo en otros más específicos que hemos distinguido en dos ámbitos, y se detallan a continuación. 
- Ámbito familiar y personal:

- Favorecer la creación de rutinas y lazos familiares en torno a la lectura de cuentos infantiles.

- Fomentar el gusto por la lectura y crear hábitos entre nuestro alumnado.

- Desarrollar la competencia lingüística aumentando el vocabulario, la fluidez, la expresión y la comprensión lectora.

- Aprender a cuidar y respetar el material prestado.

- Aportar trabajo y material a un proyecto con la finalidad de enriquecerlo.

- Compartir los sentimientos generados por la lectura y, a su vez, respetar y escuchar las opiniones e intereses de los demás.

- Relacionar experiencias lectoras con objetos y sonidos de forma que puedan transmitir información previa a los siguientes lectores y entre todos enriquezcan la historia.

- Desarrollar la creatividad e imaginación.

- Mejorar la relación entre los lectores de un mismo cuento, ya que cada uno aportará sus sensaciones o vivencias de la historia que ha leído y/o escuchado, para que aporten información.

- Proporcionar cuentos adaptados y materiales complementarios relacionados con los mismos, favoreciendo la manipulación.

- Desarrollar la atención y el respeto por lo que han aportado otros lectores.

- Tener acceso a los cuentos en braille de la Tifloteca, independientemente de la localidad en la que vivan.

- Ámbito escolar:

- Mejorar la inclusión de los alumnos con discapacidad visual en sus aulas. 
- Potenciar la relación familia-entorno educativo.

- Desarrollar la atención y el respeto por lo que han aportado otros compañeros.

- Acercar al resto de la comunidad educativa el código de lectoescritura braille.

\section{Población destinataria de la experiencia}

Este proyecto está pensado para llevarlo a la práctica con alumnos del segundo ciclo de educación infantil y primer ciclo de educación primaria que sean o vayan a ser usuarios de braille.

En el presente curso, El cuento viajero cuenta con la participación de cuatro alumnos, pertenecientes a las siguientes etapas educativas:

- Tres pertenecientes a la etapa del segundo ciclo de educación infantil.

- Uno perteneciente al primer ciclo de educación primaria.

\section{Temporalización y fechas de realización}

Esta actividad comenzó a realizarse en 2016, manteniéndose hasta la actualidad. Tiene un período trimestral. El cuento permanece, como préstamo, 90 días, estando durante este tiempo en el entorno familiar, para que el alumnado lo pueda llevar a su colegio, donde lo presenta, enseña y comenta, antes de volver a viajar a otro alumno o alumna y su familia.

\section{Metodología}

Para fomentar la motivación a la lectura en nuestro alumnado se lleva a cabo una actividad: El cuento viajero, en la que hay un intercambio de cuentos adaptados, tanto de la Tifloteca como los elaborados por el equipo educativo, que se llevan a casa para la lectura con ayuda de los padres, porque el ámbito familiar es uno de los principales agentes para estimular la lectura desde las primeras edades. Los cuentos que se seleccionan tienen unas características esenciales, como resultado de la unión entre 
texto en braille y tinta e ilustración en relieve. Este doble código es muy válido para la lectura porque permite interpretar y compensar las lagunas de comprensión.

\subsection{Actividades y estrategias metodológicas}

Este proyecto favorece y fomenta la transmisión de experiencias, las actividades y la comunicación entre padres e hijos, donde las familias se implican, participan y colaboran.

Figura 2. Niña abriendo la bolsa de materiales del cuento Mila y sus juguetes

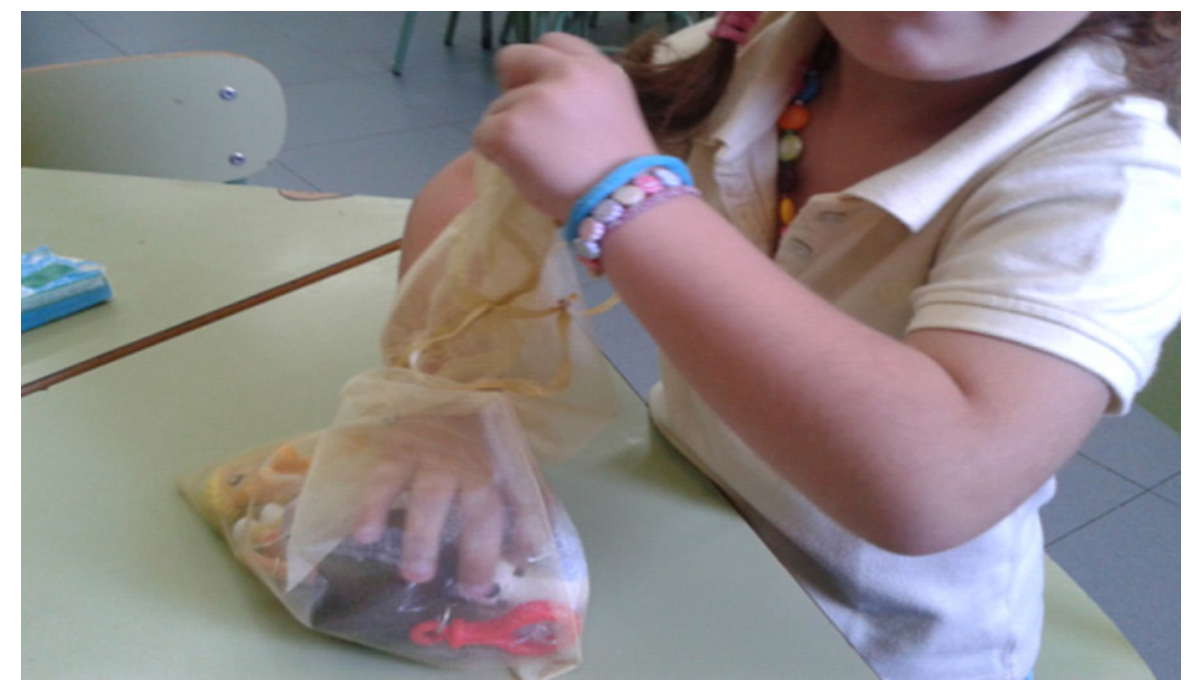

Todas las actividades que se realizan contribuyen al desarrollo de las competencias clave: lingüística, cultural y artística, autonomía e iniciativa personal, social y ciudadana. Concretamente, las actividades desarrolladas han sido:

- Lectura del cuento por parte del padre o la madre.

- Lectura en voz alta del cuento de aquellos alumnos que ya comienzan a leer, para familiarizarse con el texto.

- Lectura compartida con familia y compañeros.

- Actividades de comprensión lectora, como explicarlo a los demás, identificar y localizar los elementos en relieve del cuento, responder preguntas relacionadas con la historia, aprender canciones, etc. 
- Manipulación de los personajes y objetos más significativos de cada uno de los cuentos (Figura 2).

- Elaboración de material relacionado con la lectura del cuento por parte de la familia y del alumno, como dibujar o moldear plastilina.

Para los cuentos elaborados por el equipo educativo, se tuvieron en cuenta las siguientes estrategias metodológicas:

- Lectura, por parte de un adulto, para construir la comprensión y las habilidades esenciales para el aprendizaje de la lectura.

- Implementación de estrategias para asegurar su comprensión, expresión, entonación y ritmo.

- Adaptación de los cuentos, tanto en tinta como en braille, para facilitar su lectura por parte de las familias que aún no conocen el código braille.

- La escritura, en algunos de ellos, se realiza sin utilizar mayúsculas, ni sílabas trabadas e inversas, y utilizando un interlineado doble.

- Manipulación de los personajes y objetos más significativos del cuento para el reconocimiento táctil y sensorial.

- Uso de múltiples vías sensoriales para el aprendizaje.

- La motivación será clave en este proyecto y conducirá al alumnado a una situación que facilite su aprendizaje (Bilbao, 2015).

- La selección de los cuentos estará determinada no solo por la edad del alumnado sino también por sus centros de interés.

\subsection{Recursos empleados}

Personales. Equipo educativo, especialista de adaptación documental, alumnado, familias y profesionales de los centros educativos. 
Cuentos. Contamos con dos tipos de recursos:

- Cuentos elaborados por el equipo educativo, escritos en braille y en tinta, con muy poco texto por cada hoja, tanto adaptados de cuentos clásicos populares ( $E$ I flautista de Hamelín, El gato con botas...) como inventados (Pipo y el diente, Mila y sus juguetes, Los amigos de Pope...) (Figura 3).

Todos ellos cuentan con una bolsa con material complementario (juguetes, objetos reales...) que favorecen la comprensión de los mismos y permiten acercarse a los cuentos de forma lúdica y divertida.

Se utilizaron diversos materiales para su adaptación: pegamento, tijeras, papeles y telas de diferentes texturas, goma eva, hojas secas, piedras, cartones, objetos/ juguetes simbólicos, máquina Perkins, ordenador, papel de braille e impresora en braille y tinta.

Figura 3. Fotografía del cuento, elaborado por el equipo educativo, Los amigos de Pope

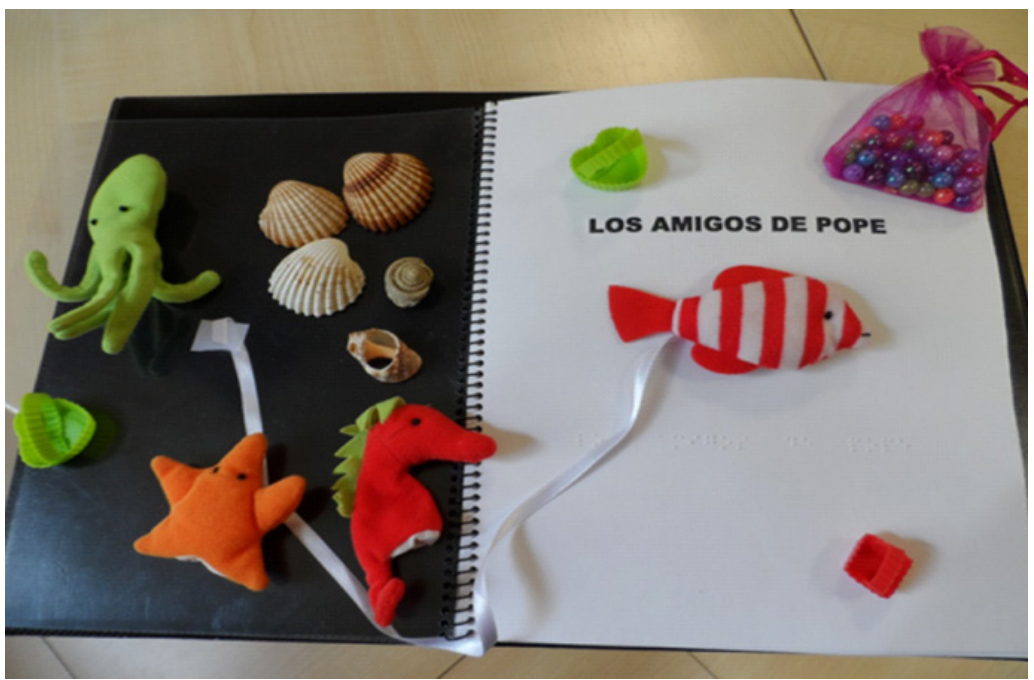

- Cuentos infantiles de la Tifloteca, valorando, para cada niño, cuál es el más adecuado por edad o por preferencias, contando con la motivación como hilo conductor (Bubo, Caen las hojas, Como huevos en la huevera, ¿Conoces la magia de Marit?, Corre ratón, corre, iHay que soñar!, El caracol Serafín, La pulga Leocadia, El huevito con patas, El pez arcoíris, El regalo, Papá pierde las gafas, Pau juega a goalball, Por cuatro esquinitas de nada, 10 viajes y 1 sueño). 


\section{Resultados}

Se valora positivamente la implementación de esta actividad, ya que, desde su puesta en marcha, hemos constatado un aumento de la lectura por parte de nuestro alumnado, cumpliendo así el objetivo general: fomentar la lectura entre el alumnado con discapacidad visual.

Tras la puesta en marcha del proyecto se han constatado los siguientes beneficios:

- Se potencian habilidades y destrezas (físicas, cognitivas, comunicativas...), que afectan a la salud física y mental del niño, ya que pueden llegar a ser capaces de concentrarse durante más tiempo y comunicarse con mayor facilidad.

- Se fomenta la inclusión, la participación y la comunicación con sus iguales en el centro educativo.

- Se impulsan valores positivos relacionados con la escucha activa, el reconocimiento de emociones, la creatividad y el respeto tanto hacia el material como a las opiniones de los demás.

- Se mejora la relación afectiva entre los padres y el niño, promoviendo los vínculos familiares y generando una mejoría en su calidad de vida.

- Se facilita una coordinación y comunicación más efectiva entre los maestros y las familias, favoreciendo el aprendizaje del sistema braille y estableciendo pautas comunes de actuación.

\section{Conclusiones}

Sin duda, parte del éxito de esta actividad está en su carácter motivador y en la buena acogida que ha tenido por parte de las familias, reflejando no solo el interés por compartir conocimientos con los más pequeños, sino el realizar un proyecto común entre padres, niños y medio escolar.

Es importante reseñar que el papel que debe desempeñar la familia como medio educador es fundamental, y que el colegio actúa complementándolo. La familia asume 
sus compromisos de estimular y propiciar aprendizajes, hábitos sociales y valores adecuados, cuidando la relación con los más pequeños, potenciando la comunicación y ofreciendo los medios adecuados.

En cuanto a la difusión del braille, observamos que puede hacerse en todos los círculos sociales en los que participa nuestro alumnado (familiares, colegio, vecinos, amigos...), contribuyendo de forma relevante a la importancia que tiene como elemento inclusivo.

Además, se pretende reimpulsar el braille como código de lectoescritura que evoluciona con los tiempos.

En el desarrollo de esta actividad, destacamos los siguientes logros:

- Valoración de las necesidades detectadas en la población atendida y propuesta de actividades para dar respuesta a las mismas.

- Difusión entre los maestros del equipo educativo de aquellos cuentos adaptados para el alumnado que el SBO lleva a cabo, de tal manera que los maestros pueden conocer de primera mano estos cuentos y divulgarlos entre los padres de sus alumnos y en los centros educativos donde se encuentran matriculados.

- Fomento del uso de la Tifloteca y sus recursos a través de la finalidad de ocio y cultura, pues consideramos que es una buena herramienta para que maestros y padres de alumnos conozcan las existencias de materiales que hay en ella.

- Organización de talleres de iniciación para padres de alumnos afiliados a raíz de esta actividad, iniciándolos en el sistema braille para que se impliquen en el proceso de aprendizaje del código braille de sus hijos.

- Creación de actividades adicionales a raíz de la puesta en práctica de la actividad El cuento viajero, concretamente, de un cuentacuentos adaptado con pictogramas de texturas (Figura 4).

- Personalización de los cuentos para atender las necesidades de un mayor número de alumnos aportándoles material de elaboración propia. 
- Reimpulso del sistema braille, motivando su lectura, fomentando su conocimiento y dando a conocer en centros docentes cómo son los cuentos de nuestros alumnos.

- Transmisión de una imagen del sistema braille acorde con los tiempos, atractiva y compatible con el uso de las tecnologías y, en definitiva, útil y moderna.

Gracias a los resultados obtenidos, se continúa desarrollando esta experiencia.

Figura 4. Mural con pictogramas

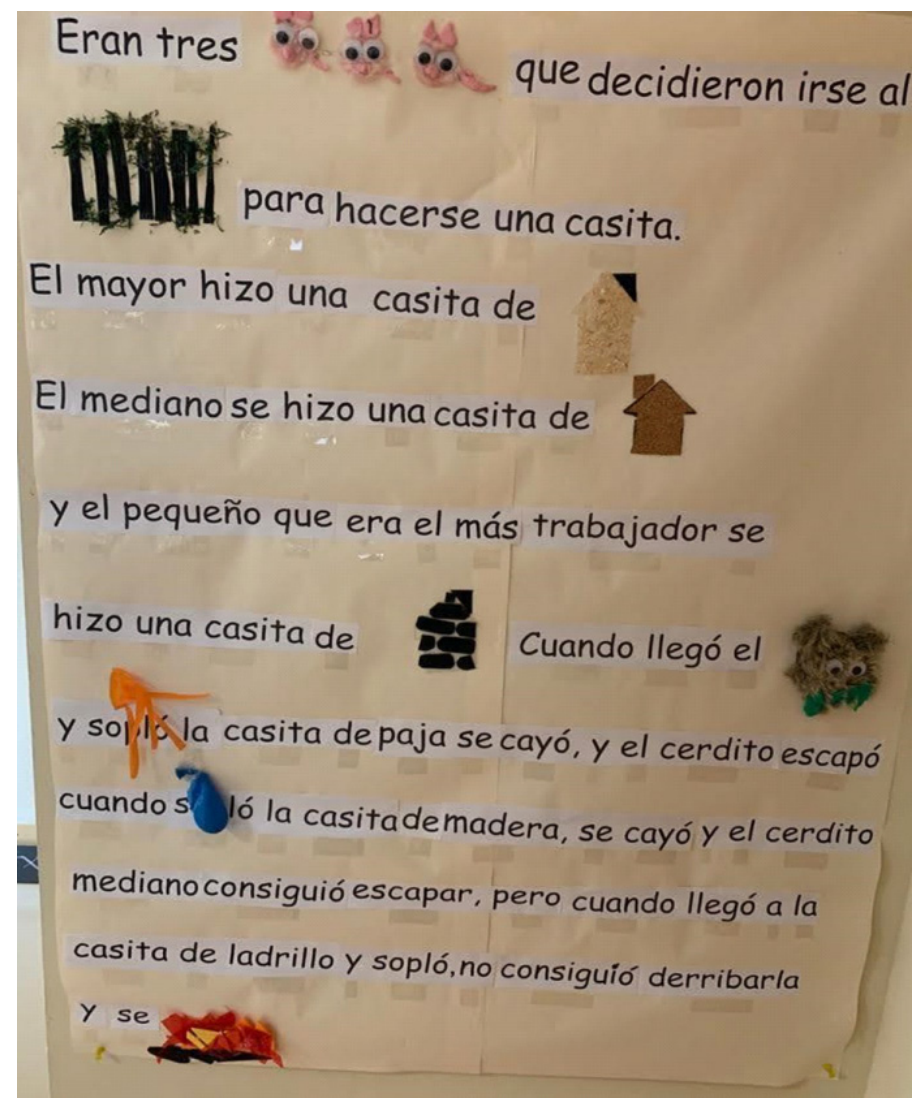

\section{Referencias bibliográficas}

Bilbao, A. (2015). El cerebro del niño explicado a los padres. Plataforma Editorial.

Boix, T., y Viché, M. (1990). Animación y gestión cultural. Grup Dissabte. 
Simón, C. (1994). El desarrollo de los procesos básicos en la lectura braille [Word]. Organización Nacional de Ciegos Españoles.

M. ${ }^{a}$ Isabel Alcántara Moreno. Maestra. Dirección de Apoyo (DAP) de la ONCE en Jaén. Calle Mesa, 16; 23001 Jaén (España). Correo electrónico: iam@once.es.

Fátima Bello Díaz. Maestra. Dirección de Apoyo (DAP) de la ONCE en Jaén. Calle Mesa, 16; 23001 Jaén (España). Correo electrónico: fabd@once.es.

Joaquín Blanca Castillo. Especialista de la Unidad de Adaptación Documental (UAD). Dirección de Apoyo (DAP) de la ONCE en Jaén. Calle Mesa, 16; 23001 Jaén (España). Correo electrónico: jobc@once.es.

M. ${ }^{a}$ Belén Díaz Corpas. Maestra. Dirección de Apoyo (DAP) de la ONCE en Jaén. Calle Mesa, 16; 23001 Jaén (España).Correo electrónico: madic@once.es.

M. ${ }^{a}$ Carmen Fernández Fernández. Maestra. Dirección de Apoyo (DAP) de la ONCE en Jaén. Calle Mesa, 16; 23001 Jaén (España). Correo electrónico: mffe@once.es.

Asunción Gámez Martos. Maestra. Dirección de Apoyo (DAP) de la ONCE en Jaén. Calle Mesa, 16; 23001 Jaén (España).Correo electrónico: asgm@once.es.

M. ${ }^{a}$ Dolores López Albusac. Maestra. Dirección de Apoyo (DAP) de la ONCE en Jaén. Calle Mesa, 16; 23001 Jaén (España).Correo electrónico: mdla@once.es.

Antonio Moreno Batres. Maestro. Dirección de Apoyo (DAP) de la ONCE en Jaén. Calle Mesa, 16; 23001 Jaén (España). Correo electrónico: amob@once.es. 